\title{
PROFIL PERKEMBANGAN SOSIAL ANAK KELOMPOK B DALAM BERMAIN PERAN
}

\author{
Mutiara Sari Dewi \\ Universitas Islam Malang \\ e-mail: mutiara.sari@unisma.ac.id
}

Diterima: 21 Mei 2019 | Direvisi: 24 Mei 2019 | Disetujui: 28 Mei 2019 (C) 2019 Pendidikan Guru Raudhatul Atfhal Fakultas Agama Islam Universitas Islam Malang

\begin{abstract}
Social development is one aspect of development that must be stimulated early. Based on observational data made regarding the daily lives of group B children at Ar-Rahman Kindergarten, Jombang, it appears that children are better able to socialize with peers or with people who are older than children from other institutions. One form of stimulus for social development in kindergarten, specifically for children aged 5-6 years (group B) kindergarten can be done through role playing.

This research is a research with descriptive quantitative research. Data analysis techniques use descriptive with percentage. The study was conducted in group B, TK Ar-Rahman, Jombang Regency with a sample of 56 children.

Based on the results of these studies, it can be concluded that the profile of social development of child B, TK Ar-Rahman Jombang, is in good category ( $\sqrt{\mathrm{s}} \mathrm{s}$ 3) on indicators: 1) able to support with friends; 2) purchase at game level; and 3) able to ask and answer questions. Each indicator, category ( children (57.1\%) worked together in role playing activities to become family members with only 1 (one) command. 34 children (60.7\%) were able to obey 3 (two) rules of the game in role playing. 28 children (50\%) were able to ask and answer questions while playing roles.
\end{abstract}

Keyword: Social development, role playing, 5 - 6 years.

This work is licensed under Creative Commons Attribution Non Commercial 4.0 International License Available online on: http://riset.unisma.ac.id/index.php/fai/index 


\section{A. Pendahuluan}

Pada rentang usia 0 - 6 tahun, anak mengalami masa sensitif untuk menerima upaya perkembangan seluruh potensi yang ada dalam dirinya. Potensi dalam diri anak berkaitan dengan setiap aspek perkembangan yang dibawa sejak anak dalam kandungan. Salah satu aspek perkembangan perlu distimulasi sejak dini yaitu perkembangan sosial. Perkembangan sosial merupakan aspek perkembangan yang berkaitan dengan perilaku sosial sesuai dengan aturan norma sosial yang berlaku.

North American Association for Enviromental Education (dalam buku Early Childhood Enviromental Education Program) menyatakan socialemotional development refers to social competencies such as empathy, communication, and cooperation as well as intrapersonal processes such as emotion recognition, coping with emotions, and regulating emotion and behavior to match the demands of the context (Education, 2000)

Dalam pendapat tersebut tampak bahwa perkembangan sosial berkaitan dengan kemampuan berempati, komunikasi, bekerja sama, serta proses intrapersonal seperti pengenalan emosi, menghadapi emosi, dan mengatur emosi. Sejalan dengan pendapat tersebut, dalam Permendiknas No 146 Tahun 2014 diungkapkan bahwa indikator dari perkembangan sosial anak, khususnya usia 5 6 tahun, diantaranya: 1) anak mampu membantu teman; 2) anak mampu mentaati aturan permainan; 3) anak mampu bertanya dan menjawab pertanyaan (Kemendikbud, 2015).

Semua kemampuan yang berkaitan dengan perkembangan sosial tersebut perlu untuk distimulus atau diberikan rangsangan agar perkembangan sosial anak mengarah pada perilaku yang membuat anak diterima di lingkungannya. Sujiono (2005) juga mengungkapkan beberapa alasan mengapa anak perlu mempelajari perilaku sosial: (1) agar anak dapat belajar bertingkah laku yang dapat diterima lingkungannya, (2) agar anak dapat memerankan peranan sosial yang dapat diterima kelompoknya, (3) agar anak dapat mengembangkan sikap sosial yang sehat terhadap lingkungannya yang merupakan modal penting untuk sukses dalam kehidupan sosialnya kelak, dan (4) agar anak mampu menyesuaikan dirinya dengan baik, dan akhirnya lingkungannya pun dapat menerima dia dengan senang hati.

Berdasarkan pendapat tersebut, perkembangan sosial anak sangat penting untuk diberikan stimulus agar berkembang optimal. Salah satu bentuk stimulus dapat diupayakan melalui pembelajaran yang membuat anak berinteraksi, 
bermain dengan temannya. Namun, bukanlah hal yang mudah menciptakan lingkungan belajar yang mampu mendorong berkembangnya kedua aspek perkembangan tersebut. Masitoh (2012) mengungkapkan bahwa pembelajaran untuk anak usia dini, khususnya di TK perlu menyediakan berbagai kegiatan yang dapat mengembangkan berbagai aspek perkembangan yang meliputi kognitif, bahasa, sosial, emosi, fisik, dan motorik.

Kegiatan di TK yang beragam untuk tujuan mengembangkan berbagai aspek perkembangan dapat diterapkan menggunakan metode pembelajaran yang sesuai dengan karakteristik, kebutuhan anak, dan tujuan pembelajaran. Salah satunya melalui bermain peran (role playing). Beberapa hasil penelitian menunjukkan bahwa bermain peran merupakan cara mempraktikan keterampilan sosial dasar (Branch, 2011; Brown, 1981; Kilgour et al., 2015). Rowell (2010) dalam penelitiannya mengungkapkan bahwa bermain peran bagi anak usia 5 - 6 tahun mampu mencerminkan kehidupan sosial sekitar anak seperti keluarga, budaya, atau komunitas sekitar anak, selain itu imajinasi anak akan berkembang sangat liar.

Role-play involves the next development of this imaginative play, where a child is able to 'become' someone or something else. In taking on a role a child sees how it feels to have another point of view, and learns that the world looks different to different people (Stage, 2009).

Berdasarkan paparan tersebut, tampak keterkaitan positif dari bermain peran dan perkembangan sosial anak usia dini, khusus 5 - 6 tahun. Hal menarik lainnya yang melatarbelakangi penelitian ini, yaitu hasil obervasi yang telah dilakukan di TK Ar-Rahman, Kabupaten Jombang. Berdasarkan data observasi yang dilakukan terkait keseharian anak kelompok B, tampak bahwa dari 56 terdapat lebih dari 30 anak mampu bersosialisasi dengan teman sebaya ataupun dengan orang yang lebih tua. Dalam beberapa kesempatan aktivitas diluar sekolah, anak tampak lebih percaya diri dibandingkan anak dari lembaga pendidikan Islam anak usia dini, khususnya RA lain. Anak lebih mampu mematuhi peraturan yang telah disepakati antara guru dan anak ataupun dengan teman sebaya.

Dalam kegiatan pembelajaran, TK Ar-Rahman menggunakan model pembelajaran sentra, dengan salah satu sentra yang menarik perhatian peneliti yaitu sentra bermain peran. Saat anak aktivitas pada sentra bermain peran, kemampuan anak dalam berosialisasi lebih tampak menonjol daripada di sentra lainnya. Hal ini pula yang mendasari peneliti melakukan penelitian terkait profil perkembangan sosial anak dalam aktivitas bermain peran. 
Keterkaitan teori dan adanya fakta di TK Ar-Rahman tersebut menjadi suatu hal yang menarik bagi peneliti untuk meneliti lebih lanjut terkait profil perkembangan sosial anak usia 5 -6 tahun (kelompok B) dalam aktivitas bermain peran di TK Islam Ar-Rahman, Jombang. Peneliti berharap hasil penelitian ilmiah ini, mampu memberi bukti konkrit terkait perkembangan sosial anak kelompok B dalam aktivitas bermain peran, sehingga mampu memberi konstribusi positif keilmuan pendidikan anak usia dini.

\section{B. Metode}

Penelitian ini merupakan penelitian dengan jenis penelitian kuantitatif deskriptif. Adapun indikator penilaiannya sebagai berikut.

Tabel 1. Indikator Penilaian Perkembangan Sosial Anak Kelompok B

\begin{tabular}{|c|l|l|}
\hline No & \multicolumn{1}{|c|}{ Indikator } & \multicolumn{1}{|c|}{ Kegiatan } \\
\hline 1. & Saling membantu dengan teman. & $\begin{array}{l}\text { Bekerja sama dalam kegiatan bermain } \\
\text { peran menjadi anggota keluarga }\end{array}$ \\
\hline 2. & Mentaati aturan permainan & $\begin{array}{l}\text { Mentaati aturan permainan, } \\
\text { khususnya dalam bermain peran }\end{array}$ \\
\hline 3. & $\begin{array}{l}\text { Berani bertanya dan menjawab } \\
\text { pertanyaan. }\end{array}$ & $\begin{array}{l}\text { Berani bertanya dan menjawab } \\
\text { pertanyaan saat bermain peran }\end{array}$ \\
\hline
\end{tabular}

Penelitian ini dilakukan di TK Ar-Rahman, Kabupaten Jombang selama 1 (satu) bulan. Populasi penelitian yaitu anak kelompok B TK Ar-Rahman berjumlah 70 anak. Teknik pengambilan sampel menggunakan purposive sampling menghasilkan 56 anak terpilih menjadi sampel penelitian. Teknik pengumpulan data yang digunakan yaitu observasi dan dokumentasi. Adapun instrument penelitan yang digunakan dalam observasi, sebagai berikut.

Tabel 2. Instrumen Penelitian Pencapaian Perkembangan Sosial

\begin{tabular}{|l|lr|l|l|l|l|}
\hline No & Kegiatan & \multicolumn{5}{|c|}{ Skor Penilaian } \\
\cline { 4 - 7 } & & \multicolumn{2}{|c|}{$\mathbf{1}$} & \multicolumn{2}{|c|}{$\mathbf{2}$} & \multicolumn{1}{|c|}{$\mathbf{4}$} \\
\hline 1. & Bekerja & sama & Anak tidak & Anak bekerja & Anak bekerja & Anak bekerja \\
& dalam & kegiatan & mampu & sama dalam & sama dalam & sama dalam \\
& bermain & peran & bekerja sama & kegiatan & kegiatan & kegiatan \\
& menjadi anggota & dalam & bermain peran & bermain peran & bermain peran \\
& keluarga & & kegiatan & menjadi & menjadi & menjadi \\
\hline
\end{tabular}




\begin{tabular}{|c|c|c|c|c|c|}
\hline \multirow[t]{2}{*}{ No } & \multirow[t]{2}{*}{ Kegiatan } & \multicolumn{4}{|c|}{ Skor Penilaian } \\
\hline & & 1 & 2 & 3 & 4 \\
\hline & & $\begin{array}{l}\text { bermain } \\
\text { peran } \\
\text { menjadi } \\
\text { anggota } \\
\text { keluarga }\end{array}$ & $\begin{array}{l}\text { anggota } \\
\text { keluarga } \\
\text { tetapi masih } \\
\text { dengan } \\
\text { perintang } \\
\text { guru hingga } \\
\text { berulang- } \\
\text { ulang }\end{array}$ & $\begin{array}{l}\text { anggota } \\
\text { keluarga } \\
\text { hanya dengan } \\
1 \text { (satu) kali } \\
\text { perintah }\end{array}$ & $\begin{array}{l}\text { anggota } \\
\text { keluarga tanpa } \\
\text { perintah dari } \\
\text { guru }\end{array}$ \\
\hline 2. & $\begin{array}{l}\text { Mentaati aturan } \\
\text { permainan, } \\
\text { khususnya dalam } \\
\text { bermain peran }\end{array}$ & $\begin{array}{l}\text { Anak hanya } \\
\text { mampu } \\
\text { mentataati } 1 \\
\text { (satu) aturan } \\
\text { permainan } \\
\text { dalam } \\
\text { bermain } \\
\text { peran }\end{array}$ & $\begin{array}{l}\text { Anak mampu } \\
\text { mentaati } 2 \\
\text { (dua) aturan } \\
\text { permainan } \\
\text { dalam } \\
\text { bermain peran }\end{array}$ & $\begin{array}{l}\text { Anak mampu } \\
\text { mentaati } 3 \\
\text { (dua) aturan } \\
\text { permainan } \\
\text { dalam } \\
\text { bermain peran }\end{array}$ & $\begin{array}{l}\text { Anak mampu } \\
\text { mentaati lebih } \\
\text { dari } 3 \text { (dua) } \\
\text { aturan } \\
\text { permainan } \\
\text { dalam bermain } \\
\text { peran }\end{array}$ \\
\hline 3. & $\begin{array}{l}\text { Berani bertanya } \\
\text { dan menjawab } \\
\text { pertanyaan saat } \\
\text { bermain peran }\end{array}$ & $\begin{array}{l}\text { Anak belum } \\
\text { mampu } \\
\text { bertanya dan } \\
\text { menjawab } \\
\text { pertanyaan } \\
\text { saat bermain } \\
\text { peran }\end{array}$ & $\begin{array}{l}\text { Anak mampu } \\
\text { bertanya atau } \\
\text { menjawab } \\
\text { pertanyaan } \\
\text { saja saat } \\
\text { bermain peran }\end{array}$ & $\begin{array}{l}\text { Anak mampu } \\
\text { bertanya dan } \\
\text { menjawab } \\
\text { pertanyaan } \\
\text { saat bermain } \\
\text { peran, tetapi } \\
\text { masih belum } \\
\text { sesuai konteks } \\
\text { pertanyaan }\end{array}$ & $\begin{array}{l}\text { Anak mampu } \\
\text { bertanya dan } \\
\text { menjawab } \\
\text { pertanyaan } \\
\text { saat bermain } \\
\text { peran dengan } \\
\text { tepat. }\end{array}$ \\
\hline
\end{tabular}

Teknik analisis data menggunakan analisis deksriptif dengan persentase untuk mengetahui profil perkembangan sosial anak kelompok B. Adapun rumus yang digunakan sebagai berikut.

$$
\mathrm{P}=\frac{F}{N} \times 100 \%
$$

Keterangan:

$\mathrm{P}=$ persentase yang dicari

$F=$ frekuensi

$N=$ jumlah responden 


\section{Hasil dan Pembahasan}

1. Hasil Penelitian Profil Perkembangan Sosial Anak Kelompok B Di TK Ar-Rahman.

Penelitian ini merupakan penelitian deskriptif, sehingga hasil penelitian tentang profil perkembangan soaial anak kelompok B TK ArRahman, perlu dideksripsikan secara menyeluruh maupun setiap indikator. Adapun hasil penelitian setiap indikator diperoleh data sebagai berikut.

Tabel 3. Distribusi Frekuensi Perkembangan Sosial Anak Kelompok B dalam Indikator Bekerja Sama dengan Teman

\begin{tabular}{|c|c|c|c|}
\hline $\begin{array}{c}\text { Kelas } \\
\text { Penilaian }\end{array}$ & Kriteria Penilaian & Frekuensi & Persentase \\
\hline$\sum 1$ & $\begin{array}{l}\text { Anak tidak mampu bekerja sama } \\
\text { dalam kegiatan bermain peran } \\
\text { menjadi anggota keluarga }\end{array}$ & 4 & $7,1 \%$ \\
\hline 牙2 & $\begin{array}{l}\text { Anak bekerja sama dalam kegiatan } \\
\text { bermain peran menjadi anggota } \\
\text { keluarga tetapi masih dengan } \\
\text { perintang guru hingga berulang- } \\
\text { ulang }\end{array}$ & 7 & $12,5 \%$ \\
\hline 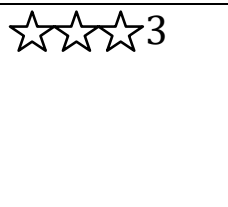 & $\begin{array}{l}\text { Anak bekerja sama dalam kegiatan } \\
\text { bermain peran menjadi anggota } \\
\text { keluarga hanya dengan } 1 \text { (satu) kali } \\
\text { perintah }\end{array}$ & 32 & $57,1 \%$ \\
\hline 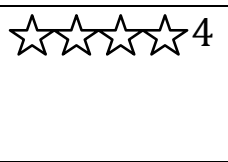 & $\begin{array}{l}\text { Anak bekerja sama dalam kegiatan } \\
\text { bermain peran menjadi anggota } \\
\text { keluarga tanpa perintah dari guru }\end{array}$ & 13 & $23,2 \%$ \\
\hline
\end{tabular}

Berdasarkan tabel tersebut tampak bahwa perkembangan sosial anak dalam hal bekerjasama dengan teman yaitu 4 (7,1\%) anak tidak mampu bekerja sama dalam kegiatan bermain peran menjadi anggota keluarga; 7 anak $(12,5 \%)$ anak bekerja sama dalam kegiatan bermain peran menjadi anggota keluarga tetapi masih dengan perintang guru hingga berulang-ulang; 32 anak $(57,1 \%)$ bekerja sama dalam kegiatan bermain peran menjadi anggota keluarga hanya dengan 1 (satu) kali perintah; 13 anak $(23,2 \%)$ anak bekerja sama dalam kegiatan bermain peran menjadi anggota keluarga tanpa perintah dari guru. Frekuensi terbanyak terletak 
pada kategori anak bekerja sama dalam kegiatan bermain peran menjadi anggota keluarga hanya dengan 1 (satu) kali perintah (

3).

Tabel 4. Distribusi Frekuensi Perkembangan Sosial Anak Kelompok B dalam Indikator Mentaati Aturan Permainan

\begin{tabular}{|c|c|c|c|}
\hline $\begin{array}{c}\text { Kelas } \\
\text { Penilaian }\end{array}$ & Kriteria Penilaian & Frekuensi & Persentase \\
\hline 它1 & $\begin{array}{l}\text { Anak hanya mampu mentaati } 1 \\
\text { (satu) aturan permainan dalam } \\
\text { bermain peran }\end{array}$ & 0 & $0 \%$ \\
\hline$\hat{x}^{2}$ & $\begin{array}{l}\text { Anak mampu mentaati } 2 \text { (dua) } \\
\text { aturan permainan dalam bermain } \\
\text { peran }\end{array}$ & 15 & $26,7 \%$ \\
\hline 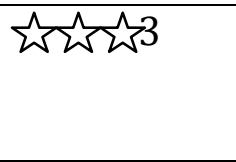 & $\begin{array}{l}\text { Anak mampu mentaati } 3 \text { (dua) } \\
\text { aturan permainan dalam bermain } \\
\text { peran }\end{array}$ & 34 & $60,7 \%$ \\
\hline 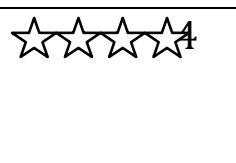 & $\begin{array}{l}\text { Anak mampu mentaati lebih dari } 3 \\
\text { (dua) aturan permainan dalam } \\
\text { bermain peran }\end{array}$ & 7 & $12,5 \%$ \\
\hline
\end{tabular}

Berdasarkan tabel tersebut tampak bahwa perkembangan sosial anak pada indikator kemampuan mentaati aturan permainan, yaitu: tidak ada (0\%) anak yang hanya mampu mentaati 1 (satu) aturan permainan dalam bermain peran; 15 anak (26,7\%) mampu mentaati 2 (dua) aturan permainan dalam bermain peran; 34 anak $(60,7 \%)$ mampu mentaati 3 (dua) aturan permainan dalam bermain peran; 7 anak (12,5\%) mampu mentaati lebih dari 3 (dua) aturan permainan dalam bermain peran. Frekuensi terbanyak terletak pada kategori mampu mentaati 3 (dua) aturan

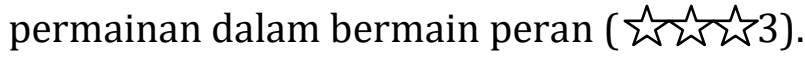

Tabel 5. Distribusi Frekuensi Perkembangan Sosial Anak Kelompok B dalam Indikator Mampu Bertanya dan Menjawab Pertanyaan

\begin{tabular}{|c|c|c|c|}
\hline $\begin{array}{c}\text { Kelas } \\
\text { Penilaian }\end{array}$ & Kriteria Penilaian & Frekuensi & Persentase \\
\hline 它1 & $\begin{array}{l}\text { Anak belum mampu bertanya dan } \\
\text { menjawab pertanyaan saat bermain } \\
\text { peran }\end{array}$ & 5 & $8,9 \%$ \\
\hline
\end{tabular}




\begin{tabular}{|c|c|c|c|}
\hline $\begin{array}{c}\text { Kelas } \\
\text { Penilaian }\end{array}$ & Kriteria Penilaian & Frekuensi & Persentase \\
\hline$\hat{x}^{2} 2$ & $\begin{array}{l}\text { Anak mampu bertanya atau } \\
\text { menjawab pertanyaan saja saat } \\
\text { bermain peran }\end{array}$ & 9 & $16 \%$ \\
\hline 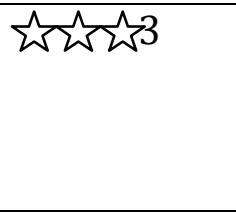 & $\begin{array}{l}\text { Anak mampu bertanya dan } \\
\text { menjawab pertanyaan saat bermain } \\
\text { peran, tetapi masih belum sesuai } \\
\text { konteks pertanyaan }\end{array}$ & 28 & $50 \%$ \\
\hline 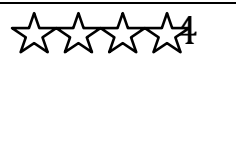 & $\begin{array}{l}\text { Anak mampu bertanya dan } \\
\text { menjawab pertanyaan saat bermain } \\
\text { peran dengan tepat. }\end{array}$ & 14 & $26 \%$ \\
\hline
\end{tabular}

Berdasarkan tabel tersebut tampak bahwa perkembangan sosial anak pada indikator mampu bertanya dan menjawab pertanyaan saat bermain peran, yaitu: 5 anak $(8,9 \%)$ belum mampu bertanya dan menjawab pertanyaan saat bermain peran; 9 anak (16\%) mampu bertanya atau menjawab pertanyaan saja saat bermain peran; 28 anak (50\%) mampu bertanya dan menjawab pertanyaan saat bermain peran, tetapi masih belum sesuai konteks pertanyaan; 14 anak (26\%) mampu bertanya dan menjawab pertanyaan saat bermain peran dengan tepat. Frekuensi terbanyak terletak pada kategori mampu bertanya dan menjawab pertanyaan saat bermain peran, tetapi masih belum sesuai konteks pertanyaan ( 象象罂).

\section{Pembahasan}

Berdasarkan hasil penelitian menunjukkan bahwa profil perkembangan sosial anak kelompok B TK Ar-Rahman, Jombang

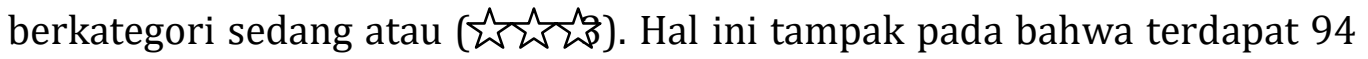

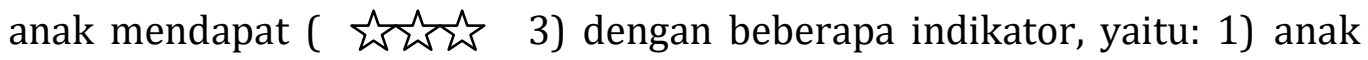
bekerja sama dalam kegiatan bermain peran menjadi anggota keluarga hanya dengan 1 (satu) kali perintah; mampu mentaati 3 (dua) aturan permainan dalam bermain peran; mampu bertanya dan menjawab pertanyaan saat bermain peran, tetapi masih belum sesuai konteks pertanyaan. Ketiga indikator tersebut.

Hal tersebut sesuai dengan pendapat (Brown, 1981; Kilgour et al., 2015) dengan hasil penelitian yang menunjukkan bahwa bermain peran merupakan cara mempraktikan keterampilan sosial dasar. Dalam penelitian 
yang dilakukan dengan hasil berdasarkan paparan yang ada, ketika anak bermain peran anak mampu mempraktikkan keterampilan dasar, diantaranya: 1) mampu bekerjasama dengan teman; 2) mampu mentaati aturan permainan; dan 3) mampu bertanya dan menjawab pertanyaan.

Pendapat lain dalam artikel yang ditulis oleh Kid Sense Child Development (2017) tertulis bahwa bermain peran merupakan salah satu aktivitas untuk mengembangkan keterampilan sosial. Dalam artikel tersebut juga disebutkan terdapat beberapa hal yang menjadi faktor berkembangnya perkembangan sosial, diantaranya: 1) bermain; 2) emosi; 3) simpati; 4) cerita kehidupan sehari - hari; serta 5) kelompok keterampilan sosial. Penerapan bermain peran dalam pembelajaran di kelompok B TK Ar-Rahman, Jombang merupakan salah satu aktivitas yang cukup baik dalam menstimulus perkembangan sosial anak. Perkembangan sosial anak yang tampak sangat berkembang didukung dengan hasil penelitian, 34 anak mendapat bintang 4 atau kategori sangat baik masingmasing indikator. Pembelajaran bermain peran di TK Ar-Rahman, Jombang tampak pada hasil dokumentasi sebagai berikut.

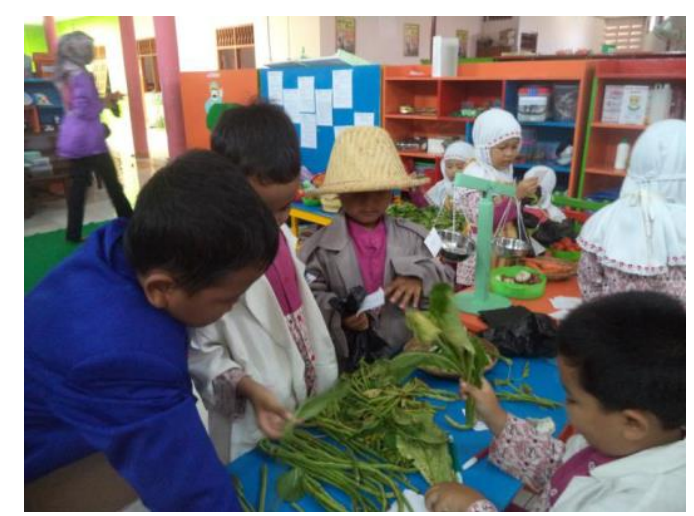

Gambar 1. Anak bermain peran di sentra bermain peran

Berdasarkan hasil dokumentasi tersebut, anak bermain peran menjadi penjual dan pembeli. Beberapa anak memerankan dirinya sebagai anggota keluarga, seperti menjadi bapak, ibu, dan anak yang sedang belanja atupun berjualan. Selain peran dari pendidik ataupun lembaga dalam menstimulus perkembangan sosial anak, dalam gambar tersebut tampak bahwa orang tua dan keluarga memiliki peran yang besar pula dan perkembangan sosial anak. Dalam penelitian yang dilakukan (Lismanda et al., 2016) bahwa orang tua dan keluarga adalah orang terdekat anak, yang memberikan konstribusi dalam perkembangan anak. Berdasarkan 
penelitian tersebut, orang tua dan keluarga juga menjadi faktor perubahan dalam perkembangan sosial anak. Bermain peran di sekolah juga sebagai bentuk imitasi anak terhadap apa yang anak lihat, dengar, dan rasakan dalam kehidupan sehari-hari. Terdapat 31 anak yang berada pada kategori cukup ( $\sqrt{2} 2$ ), berdasarkan observasi dan dokumentasi yang diperoleh peneliti, 30\% dari 31 anak disebabkan oleh faktor kurang optimalnya stimulus perilaku sosial di lingkungan keluarganya.

\section{Simpulan}

Berdasarkan hasil penelitian yang tersebut, dapat disimpulkan bahwa profil perkembangan sosial anak kelompok B, TK Ar-Rahman Jombang, dalam kategori baik ( 记证 3) pada indikator: 1) mampu bekerjasama dengan teman; 2) mematuhi aturang permainan; dan 3) mampu bertanya dan menjawab pertanyaan.

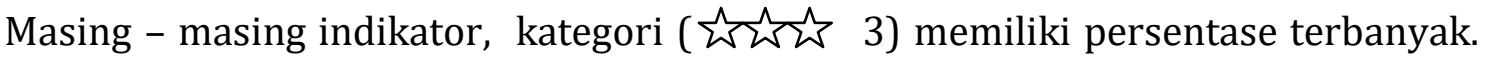
Sebanyak 32 anak $(57,1 \%)$ bekerja sama dalam kegiatan bermain peran menjadi anggota keluarga hanya dengan 1 (satu) kali perintah. 34 anak (60,7\%) mampu mentaati 3 (dua) aturan permainan dalam bermain peran. 28 anak (50\%) mampu bertanya dan menjawab pertanyaan saat bermain peran.

Adapun faktor-faktor yang mempengaruhi perkembangan sosial anak dalam bermain peran, sebagai berikut. 1) Bermain peran merupakan permainan sosial kelompok. 2) Stimulus berupa contoh dari kehidupan sehari-hari dari orang tua dan keluarga yang diterapkan anak dalam bermain peran melalui proses imitasi. 3) Anak merasakan pengalaman bermakna untuk berprilaku sosial, tanpa perasaan tertekan melalui kegiatan bermain peran.

\section{Daftar Rujukan}

Branch, S. G. (2011). Social and Role of play in social skills and intelligence of children. Procedia - Social and Behavioral Sciences, 30(1), 2272-2279. https://doi.org/10.1016/j.sbspro.2011.10.444

Brown, D. S. (1981). Role Playing Helps Develop Social Skills. Washington: WETA's Educational. Retrieved from http://www.ldonline.org/article/10141/

Education, N. A. A. for E. (2000). Guidelines for Excellence Early Childhood Environmental Education Programs. Washington: North American Association for Environmental Education (NAAEE.

Kemendikbud. (2015). Peraturan Menteri Pendidikan dan Kebudayaan Republik Indonesia Nomor 146 Tahun 2014 Tentang Kurikulum 2013 PAUD. Jakarta: Kemendikbud.

Kid Sense Child Development. (2017). Social Skills: What are Social Skills?, 1(1), 17. Retrieved from https://childdevelopment.com.au/areas-of-concern/play- 
and-social-skills/social-skills/

Kilgour, P. W., Reynaud, D., Northcote, M. T., Shields, M., Kilgour, P., Reynaud, D., ... Shields, M. (2015). Role-Playing as a Tool to Facilitate Learning, Self Reflection and Social Awareness in Teacher Education Role-Playing as a Tool to Facilitate Learning, Self Reflection and Social, 2(04), 8-20.

Lismanda, Y. F., Dewi, M. S., Anggraheni, I., Malang, U. I., Malang, U. I., \& Malang, U. I. (2016). Media Elektronik dan Pengawasan Orang Tua Sebagai Pendidikan Anti Kekerasan AUD Dalam Perspektif Psikologi. Indonesian Journal of Islamic Early Childhood Education, 1(1), 1-8. Retrieved from http://journal.ppspgra.org/index.php/Ijiece/article/view/5

Masitoh. (2012). Strategi Pembelajaran TK. Jakarta: Universitas Terbuka.

Rowell, P. (2010). The world is a child 's stage - dramatic play and children 's development, 2010(36), 16-18.

Stage, F. (2009). Learning , Playing and Interacting Learning. Runcorn: Crown Copyright. Retrieved from https://www.keap.org.uk/documents/LearningPlayingInteracting.pdf Sujiono, B. (2005). Mencerdaskan Perilaku Anak Usia Dini. Jakarta: Elex Media Computindo. 